\title{
IoT for smart home system
}

\author{
Puji Catur Siswipraptini, Rosida Nur Aziza, Iriansyah Sangadji, Indrianto, Riki Ruli A. Siregar, \\ Grace Sondakh \\ Department of Informatics, Institut Teknologi PLN, Indonesia
}

\section{Article Info}

Article history:

Received Jan 13, 2021

Revised Jun 1, 2021

Accepted Jun 5, 2021

\section{Keywords:}

ADALINE

Internet of things

Sensor

Smart home

Solar panel

\begin{abstract}
This paper examines the integration of smart home and solar panel system that is controlled and monitored using IoT (internet of things). To enable the smart home system to monitor the activity within the house and act according to the current conditions, it is equipped with several sensors, actuators, and smart appliances. All of these devices have to be connected to a communication network, so they can communicate and provide services for the smart home's inhabitants. The smart home system was first introduced to provide comfort and convenience, but later it should also address many other things, e.g. the importance of the efficient use of energy or electricity and hybrid use of energy sources. A solar panel is added to the smart home prototype and its addition is studied. Adaptive linear neural network is implemented in the prototype as an algorithm for predicting decisions based on the current conditions. The construction of the proposed integrated system is carried out through several procedures, i.e. the implementation of the adaptive linear neural network (ADALINE) as the neural network method, the design of the prototype, and the testing process. This prototype integrates functionalities of several household appliances into one application controlled by an Android-based framework.
\end{abstract}

This is an open access article under the CC BY-SA license.

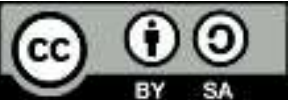

\section{Corresponding Author:}

Riki Ruli A. Siregar

Department of Informatics

Institut Teknologi PLN

Jl. Lingkar Luar Barat Duri Kosambi Jakarta Barat, Indonesia

Email: riki.ruli@itpln.ac.id

\section{INTRODUCTION}

A smart home is one of the computing and information technology applications that connects several smart objects and household devices or appliances capable of sending information and provides connections (for them) to provide services to its occupants and facilitate remote home control [1]-[3]. Thus, homeowners can control their home appliances remotely and monitor their statuses. Regarding some issues of adoption and also the potential opportunities of SHT (smart home technologies), research and development of SHT can focus on two aspects, that include technical development and how technology can be adopted and diffused into the market or society. Firstly, SHT aims to improve the quality of life at home by giving more convenient services and additional features. Secondly, this technology is used as an enhancement of a building system for better use of energy and to improve the house utilities.

The smart home system includes features that are very intelligent in today's human life and its more detailed objectives are controlling home appliances, securing connection channels between application and the embedded system, streaming real-time video from web camera or security camera, promoting home safety, and providing energy-efficient feature [4]. In smart home automation, the control of the connected household 
appliances can be carried out using smartphones [5], [6]. As wireless communication technologies have developed rapidly in recent years, it is possible to access or control household equipment remotely [7], [8].

Smart home is one of the applications of the internet of things (IoT), although IoT is also used in other areas such as in transport and traffic management [9]-[12]. The implementation of IoT for smart homes has become one of the most discussed IoT-related research areas and previous research also indicated that there was a growing number of home/household devices connected to the Internet via smartphones [13]-[15]. Also, huge data is generated by smart home devices. There are growing concerns, but previous work did not address enough to manage and analyze home data. Smart home categorization is based on focus areas, such as energy, information and communication, security, health, environment, home entertainment, and household appliances [16], [17]. In terms of energy efficiency in smart homes, several issues should be taken into consideration, i.e. energy consumption monitoring system, energy usage management, and capability for processing data related to the energy consumption around the house [6].

\section{RESEARCH METHOD}

The utilization of the artificial neural system is broader than when it was first introduced. ADALINE has several advantages, including using a linear transfer function instead of the hard-limiting one. Thus, the output can vary. ADALINE also responds to changes in its environment when it is operating. It is not only used in laboratory applications that are more likely to be based on pure science but can also be utilized in more applicable fields. Usability will be more visible if the user requires the application of artificial intelligence such as expert systems, knowledge-based systems, and decision support systems. When compared to self organizing maps (SOM), ADALINE has a different paradigm. SOM belongs to the unsupervised learning paradigm, meanwhile, ADALINE uses the supervised learning mechanism. The use of supervised learning is widely implemented on a more limited scale, but for monitoring and controlling larger quantities of smart equipment simultaneously SOM/unsupervised learning method is considered more suitable. An artificial neural network (ANN) is a network that comprises small processing units. It is a model designed to imitate human neural networks. It is an adaptive system that can change its structure to solve problems based on external or internal information that flows through the network. Simply stated, ANN is a non-linear statistical data modeling tool. that can be used to model complex relationships between inputs and outputs for finding patterns in data. Artificial neural networks are networks of small interconnected processing units, which are modeled based on neural networks. The artificial neural system is also an information processing system that has a way of working and characteristics such as neural networks in living things. This was later developed as a generalization of mathematical modeling that is patterned on the human cognitive nerve. This system will carry out derivative learning to achieve convergence. It can also be said that an artificial nervous system is a tool commonly used and applied to predict and classify. The testing algorithm for ADALINE is:

- Obtain weight from the learning process. Weight Initialization (w).

- For each bipolar input in $\mathrm{x}$ vector:

a) Set activation of the input unit $x_{i}(i=1, \ldots, n)$

b) Calculate network value (netval) from input to output

$$
\begin{aligned}
& \text { netval }=\sum_{i} x_{i} w_{i}+b \\
& y=f(\text { netval })=\text { netval }=\sum_{i} x_{i} w_{i}+b
\end{aligned}
$$

Where:

$$
\begin{array}{ll}
\text { netval } & =\text { network value } \\
b & =\text { biased value } \\
X_{i} & =\text { input data } \\
W_{i} & =\text { Weight value } \\
y & =\text { output }
\end{array}
$$

To model and match the data patterns of daily electricity consumption based on the ADALINE method, the daily energy consumption pattern is defined based on time and date. Then, it is compared with the actual data. The methodology for implementing ADALINE for the prototype is shown in Figure 1, as follows. 


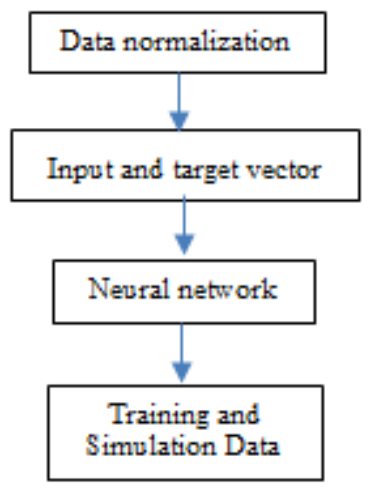

Figure 1. ADALINE testing methodology

This study has identified the problem that less implementation of an ANN system model as a mobile system that allows setting the home appliances control in one interface [18]. Normally in previous research only had automatic control, but did not yet have any function for monitoring home appliances such as a lamp, temperature, air conditioning (AC), and television (TV) [18]-[21]. The designed science and technology for humanity (STH) applies adaptive linear neural network (ADALINE) as its method, IoT, and utilizes microcontrollers, sensors, and several other supporting electronic devices [21], [22]. This microcontroller method is the hardware used to obtain a lamp controller while the ADALINE method is to get an artificial nervous system model into a system [23]-[25]. Another one is the outcomes of the smart dryer prototype can be integrated with the model of an artificial nervous system using ADALINE [26]. This prototype design initiates by inventing a scenario design to discuss the tools used and the connection between software and hardware. Software design assists in the flow of the program to be invented by connecting hardware tools, whereas hardware design is utilized to place each part that will be used [27], [28]. When this home appliances-control application has been designed, the control system is then tested to define the compliance of the application that has been made [29].

As seen in Figure 1, the ADALINE model is utilized for training the process of artificial neural networks. The targets and inputs are trained with a network that has been developed to get the learning weights to be utilized as the fundamental for calculations on the following incoming training data [30]. If the stages of normalization have been implemented, the data is ready to be processed into the ADALINE neural network [31]. When entering target data and input data as training data, the testing is performed using a neural network tool in the Matlab application and begins to create networks by training on target data and input data. From a technical point of view, several aspects need to be developed namely the user interface, smart hardware, and their software platform [32].

\section{RESULTS AND DISCUSSION}

Figure 2 shows the circuit design of the smart home system with a solar panel. The access point is used for internetwork and Raspberry Pi serves as the webserver. The mechanism of solar panels is by converting solar energy into electric current, also known as photovoltaic systems. The battery is used to store the current electricity and supply it to the household appliances as the alternative power source in the event of a power outage. The Smartphone is used as the client that can control home appliances such as choose TV Channels, turn the lights on and off, and change the speed of fan or air conditioner. The process of the client is by retrieving data to open the HTML5 Framework from the Raspberry as a computer server, both of which are connected to the access point. HyperText markup language (HTML) is used as contents written in it are easily accessed by the browsers and it offers more efficient coding. And then the Android client processes AC/Fan, the turn on and off lights, TV channel by pressing the ON button on the interface and sending this command to the access point then received by the server. As the server gives the command to the Ethernet Shield then passes it to the microcontroller, the command is received by the relay and the light will turn on. The circuit requires one chip of Raspberry as the microcontroller. The Raspberry serves as the server of data sent by the smartphone client, then forwards the command to the devices via the access point. Access points work as an intermediary between software and hardware (devices) in the process of controlling the appliances. 


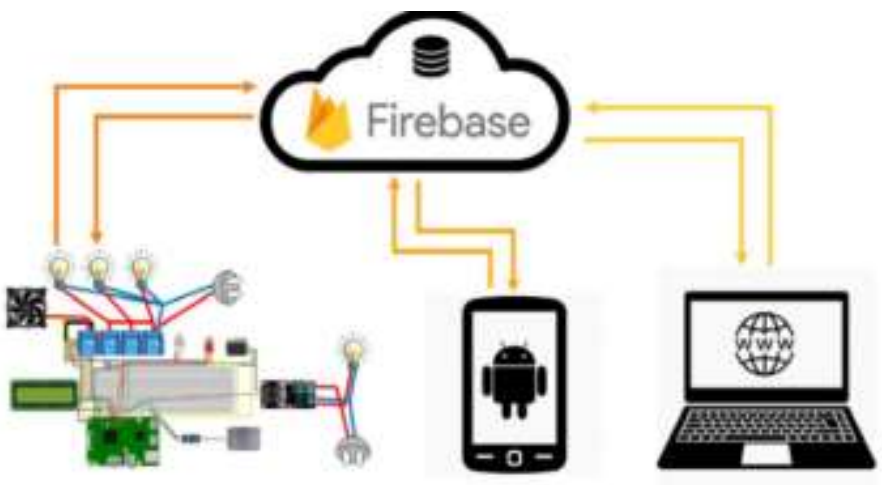

Figure 2. The circuit design of the smart home system

The process of this prototype is to model and match the data patterns of daily consumption of electrcal energy based on the adaptive linear artificial neural network method so that the definition of electrical energy daily consumption patterns based, then compare with the actual data. Tables 1 and 2 shows the behavior of the electrical load on the transmission line for electricity consumption in the area of Java, Bali, and Madura. This data was observed every hour daily for one month, in December. Thus, the dimension of the vector-matrix used for the simulation is 31 days by 24 hours, or $31 \times 24$.

Table 1. Average monthly power consumption megawatt (MW) in Java, Bali, Madura (12:30 AM - 6:00 AM)

\begin{tabular}{|c|c|c|c|c|c|c|c|c|c|c|c|c|}
\hline & \multicolumn{12}{|c|}{ HOUR } \\
\hline DAT & $12: 30$ & $1: 00$ & $1: 30$ & $2: 00$ & $2: 30$ & $3: 00$ & $3: 30$ & $4: 00$ & $4: 30$ & 5:00 & $5: 30$ & 6:00 \\
\hline E & $\mathrm{AM}$ & $\mathrm{AM}$ & AM & $\mathrm{AM}$ & $\mathrm{AM}$ & AM & $\mathrm{AM}$ & $\mathrm{AM}$ & AM & $\mathrm{AM}$ & $\mathrm{AM}$ & AM \\
\hline 1 & 12,124 & 12,086 & 11,862 & 11,672 & 11,487 & 11,381 & 11,343 & 11,357 & 11,451 & 11,520 & 11,254 & 10,468 \\
\hline 2 & 10,867 & 10,741 & 10,659 & 10,466 & 10,399 & 10,422 & 10,454 & 10,558 & 10,793 & 11,019 & 10,951 & 10,660 \\
\hline 3 & 11,596 & 11,374 & 11,285 & 11,169 & 10,973 & 11,012 & 11,003 & 11,057 & 11,320 & 11,485 & 11,300 & 10,907 \\
\hline 4 & 11,915 & 11,716 & 11,629 & 11,567 & 11,446 & 11,432 & 11,281 & 11,434 & 11,809 & 12,160 & 12,271 & 11,908 \\
\hline 5 & 12,960 & 12,783 & 12,682 & 12,527 & 12,544 & 12,381 & 12,351 & 12,456 & 12,741 & 13,129 & 13,242 & 12,752 \\
\hline 6 & 13,304 & 13,119 & 13,020 & 12,833 & 12,783 & 13,035 & 12,854 & 12,914 & 13,393 & 13,686 & 13,885 & 13,671 \\
\hline 7 & 13,484 & 13,269 & 13,131 & 12,952 & 12,890 & 12,713 & 12,723 & 13,064 & 13,144 & 13,484 & 13,651 & 13,371 \\
\hline 8 & 13,255 & 13,141 & 12,949 & 12,845 & 12,761 & 12,644 & 12,611 & 12,660 & 12,870 & 13,293 & 13,477 & 13,262 \\
\hline 9 & 13,305 & 13,058 & 12,896 & 12,729 & 12,406 & 12,248 & 12,191 & 12,255 & 12,528 & 13,082 & 13,116 & 12,770 \\
\hline 10 & 12,326 & 12,110 & 12,065 & 12,056 & 11,860 & 11,862 & 11,806 & 11,827 & 12,149 & 12,283 & 12,403 & 11,816 \\
\hline 11 & 12,160 & 11,995 & 11,892 & 11,806 & 11,659 & 11,591 & 11,570 & 11,706 & 11,921 & 12,587 & 12,754 & 12,630 \\
\hline 12 & 13,421 & 13,120 & 13,103 & 12,776 & 12,769 & 12,633 & 12,571 & 12,729 & 13,100 & 13,513 & 13,615 & 12,980 \\
\hline 13 & 13,383 & 13,036 & 12,986 & 12,886 & 12,634 & 12,610 & 12,380 & 12,536 & 12,944 & 13,264 & 13,673 & 13,485 \\
\hline 14 & 13,375 & 13,133 & 13,051 & 12,894 & 12,716 & 12,627 & 12,544 & 12,625 & 13,007 & 13,431 & 13,520 & 13,511 \\
\hline 15 & 12,922 & 12,840 & 12,675 & 12,484 & 12,437 & 12,340 & 12,245 & 12,382 & 12,647 & 13,158 & 13,504 & 13,315 \\
\hline 16 & 13,282 & 13,082 & 12,865 & 12,661 & 12,563 & 12,530 & 12,402 & 12,428 & 12,862 & 13,233 & 13,358 & 12,933 \\
\hline 17 & 12,384 & 12,259 & 12,124 & 11,996 & 11,824 & 11,758 & 11,535 & 11,638 & 11,899 & 12,206 & 12,247 & 11,718 \\
\hline 18 & 11,845 & 11,660 & 11,564 & 11,484 & 11,233 & 11,279 & 11,216 & 11,217 & 11,610 & 12,167 & 12,337 & 12,295 \\
\hline 19 & 13,224 & 12,986 & 12,793 & 12,831 & 12,639 & 12,652 & 12,510 & 12,580 & 12,838 & 13,313 & 13,559 & 13,245 \\
\hline 20 & 13,183 & 12,991 & 12,989 & 12,834 & 12,675 & 12,487 & 12,456 & 12,519 & 12,737 & 13,288 & 13,675 & 13,463 \\
\hline 21 & 13,262 & 13,139 & 12,817 & 12,609 & 12,561 & 12,508 & 12,383 & 12,414 & 12,805 & 13,231 & 13,334 & 13,374 \\
\hline 22 & 13,292 & 13,142 & 12,988 & 12,829 & 12,801 & 12,618 & 12,572 & 12,501 & 12,964 & 13,284 & 13,704 & 13,320 \\
\hline 23 & 13,240 & 13,045 & 12,815 & 12,710 & 12,601 & 12,598 & 12,353 & 12,467 & 12,730 & 13,152 & 13,461 & 12,921 \\
\hline 24 & 12,859 & 12,485 & 12,356 & 12,240 & 12,252 & 12,029 & 11,957 & 11,938 & 12,334 & 12,419 & 12,673 & 12,018 \\
\hline 25 & 12,433 & 12,243 & 12,139 & 11,925 & 11,739 & 11,740 & 11,745 & 11,786 & 12,097 & 12,583 & 12,889 & 12,569 \\
\hline 26 & 13,304 & 13,072 & 12,941 & 12,914 & 12,713 & 12,638 & 12,612 & 12,589 & 13,035 & 13,417 & 13,755 & 13,388 \\
\hline 27 & 13,349 & 13,121 & 13,059 & 12,794 & 12,872 & 12,674 & 12,648 & 12,756 & 12,974 & 13,531 & 13,931 & 13,437 \\
\hline 28 & 13,351 & 13,252 & 13,176 & 12,930 & 12,807 & 12,644 & 12,689 & 12,673 & 13,087 & 13,336 & 13,746 & 13,426 \\
\hline 29 & 13,633 & 13,421 & 13,347 & 13,210 & 13,016 & 12,806 & 12,783 & 12,918 & 13,268 & 13,567 & 13,881 & 13,644 \\
\hline 30 & 13,531 & 13,308 & 13,071 & 12,970 & 12,777 & 12,684 & 12,712 & 12,814 & 13,060 & 13,314 & 13,566 & 13,042 \\
\hline 31 & 12,486 & 12,309 & 11,986 & 12,037 & 11,929 & 11,654 & 11,668 & 11,837 & 11,955 & 12,306 & 12,439 & 11,990 \\
\hline
\end{tabular}


Table 2. Average monthly power consumption megawatt (MW) in Java, Bali, Madura (6:30 AM - 12:00 PM)

\begin{tabular}{|c|c|c|c|c|c|c|c|c|c|c|c|c|}
\hline & \multicolumn{12}{|c|}{ HOUR } \\
\hline DAT & $6: 30$ & $7: 00$ & $7: 30$ & $8: 00$ & $8: 30$ & $9: 00$ & $9: 30$ & $10: 00$ & $10: 30$ & 11:00 & $11: 30$ & $12: 00$ \\
\hline $\mathrm{E}$ & $\mathrm{AM}$ & $\mathrm{AM}$ & $\mathrm{AM}$ & $\mathrm{AM}$ & $\mathrm{AM}$ & $\mathrm{AM}$ & $\mathrm{AM}$ & $\mathrm{AM}$ & $\mathrm{AM}$ & $\mathrm{AM}$ & $\mathrm{AM}$ & $\mathrm{PM}$ \\
\hline 1 & 9,848 & 9,445 & 9,663 & 9,649 & 9,610 & 9,583 & 9,634 & 9,972 & 10,014 & 10,106 & 10,072 & 9,889 \\
\hline 2 & 10,357 & 10,383 & 10,687 & 10,997 & 11,338 & 11,691 & 11,808 & 12,184 & 12,095 & 12,120 & 12,129 & 11,963 \\
\hline 3 & 10,756 & 10,437 & 10,697 & 10,706 & 11,037 & 11,157 & 11,290 & 11,503 & 11,594 & 11,697 & 11,636 & 11,580 \\
\hline 4 & 11,787 & 12,071 & 12,673 & 13,412 & 14,146 & 14,467 & 14,677 & 14,768 & 15,123 & 15,398 & 15,227 & 14,719 \\
\hline 5 & 12,433 & 12,585 & 13,185 & 13,734 & 14,402 & 14,329 & 14,925 & 15,188 & 15,335 & 15,429 & 15,348 & 14,671 \\
\hline 6 & 13,258 & 13,193 & 13,807 & 14,207 & 14,744 & 14,979 & 15,157 & 15,459 & 15,418 & 15,575 & 15,416 & 14,906 \\
\hline 7 & 13,015 & 12,994 & 13,687 & 14,008 & 14,690 & 14,974 & 15,168 & 15,186 & 15,399 & 15,363 & 15,407 & 15,278 \\
\hline 8 & 12,908 & 12,922 & 13,453 & 14,160 & 14,631 & 14,947 & 15,114 & 15,327 & 15,447 & 15,293 & 14,756 & 13,760 \\
\hline 9 & 12,327 & 12,324 & 12,436 & 12,988 & 13,490 & 13,687 & 13,893 & 13,946 & 14,113 & 14,131 & 14,089 & 13,531 \\
\hline 10 & 11,486 & 11,272 & 11,116 & 11,418 & 11,602 & 11,675 & 11,715 & 11,855 & 11,966 & 12,012 & 11,903 & 11,630 \\
\hline 11 & 12,190 & 12,219 & 13,117 & 13,554 & 14,358 & 14,530 & 14,997 & 15,095 & 15,301 & 15,257 & 15,248 & 14,664 \\
\hline 12 & 12,936 & 12,798 & 13,682 & 14,056 & 14,575 & 14,903 & 14,951 & 15,117 & 15,441 & 15,354 & 15,296 & 14,427 \\
\hline 13 & 13,163 & 13,066 & 13,560 & 14,061 & 14,766 & 14,943 & 15,067 & 15,199 & 15,243 & 14,947 & 14,949 & 14,126 \\
\hline 14 & 13,159 & 12,944 & 13,544 & 14,197 & 14,593 & 14,950 & 15,041 & 15,186 & 15,311 & 15,380 & 15,232 & 14,598 \\
\hline 15 & 12,954 & 12,795 & 13,464 & 13,953 & 14,261 & 14,695 & 14,568 & 14,852 & 15,046 & 15,048 & 14,443 & 13,608 \\
\hline 16 & 12,492 & 12,117 & 12,591 & 12,990 & 13,370 & 13,511 & 13,565 & 13,921 & 14,126 & 14,165 & 14,007 & 13,373 \\
\hline 17 & 11,412 & 11,152 & 11,250 & 11,355 & 11,614 & 11,672 & 11,897 & 11,834 & 11,861 & 11,921 & 11,853 & 11,589 \\
\hline 18 & 12,009 & 12,098 & 12,810 & 13,454 & 13,945 & 14,199 & 14,397 & 14,622 & 14,778 & 14,872 & 14,767 & 14,348 \\
\hline 19 & 13,017 & 13,043 & 13,491 & 14,009 & 14,530 & 14,660 & 14,869 & 15,040 & 15,131 & 15,216 & 15,042 & 14,398 \\
\hline 20 & 13,075 & 12,962 & 13,656 & 13,984 & 14,633 & 14,896 & 14,982 & 15,315 & 15,346 & 15,292 & 15,343 & 14,636 \\
\hline 21 & 13,222 & 13,070 & 13,465 & 14,005 & 14,596 & 14,952 & 15,052 & 15,100 & 15,401 & 15,351 & 15,193 & 14,456 \\
\hline 22 & 12,993 & 12,974 & 13,461 & 14,097 & 14,366 & 14,893 & 15,013 & 15,290 & 15,479 & 15,430 & 14,870 & 13,907 \\
\hline 23 & 12,555 & 12,180 & 12,558 & 13,158 & 13,546 & 13,776 & 13,994 & 14,140 & 14,426 & 14,506 & 14,118 & 13,758 \\
\hline 24 & 11,585 & 11,393 & 11,558 & 11,636 & 11,896 & 11,933 & 12,168 & 12,362 & 12,420 & 12,509 & 12,293 & 12,068 \\
\hline 25 & 12,488 & 12,397 & 13,153 & 13,775 & 14,453 & 14,728 & 14,862 & 14,946 & 15,300 & 15,267 & 15,166 & 14,475 \\
\hline 26 & 13,257 & 13,222 & 13,646 & 14,599 & 15,064 & 15,085 & 15,099 & 15,210 & 15,653 & 15,359 & 15,224 & 14,755 \\
\hline 27 & 13,037 & 13,041 & 13,673 & 14,304 & 14,857 & 15,265 & 15,298 & 15,572 & 15,605 & 15,644 & 15,656 & 14,991 \\
\hline 28 & 13,207 & 13,276 & 13,641 & 14,223 & 14,753 & 15,057 & 15,177 & 15,521 & 15,631 & 15,463 & 15,384 & 14,864 \\
\hline 29 & 13,285 & 13,138 & 13,759 & 14,284 & 14,835 & 15,102 & 15,297 & 15,476 & 15,716 & 15,736 & 15,046 & 14,221 \\
\hline 30 & 12,374 & 12,187 & 12,665 & 12,927 & 13,245 & 13,524 & 13,662 & 13,895 & 14,065 & 13,890 & 13,905 & 13,598 \\
\hline 31 & 11,813 & 11,502 & 11,461 & 11,596 & 11,792 & 11,867 & 11,808 & 11,951 & 12,092 & 12,005 & 11,901 & 11,669 \\
\hline
\end{tabular}

Figure 3 shows the general 24-hour electricity consumption pattern in the area of Java, Bali, and Madura. That pattern then is normalized to get a better result. Data normalization is converting the actual value into a certain value which can then be used for determining the artificial neural network model.

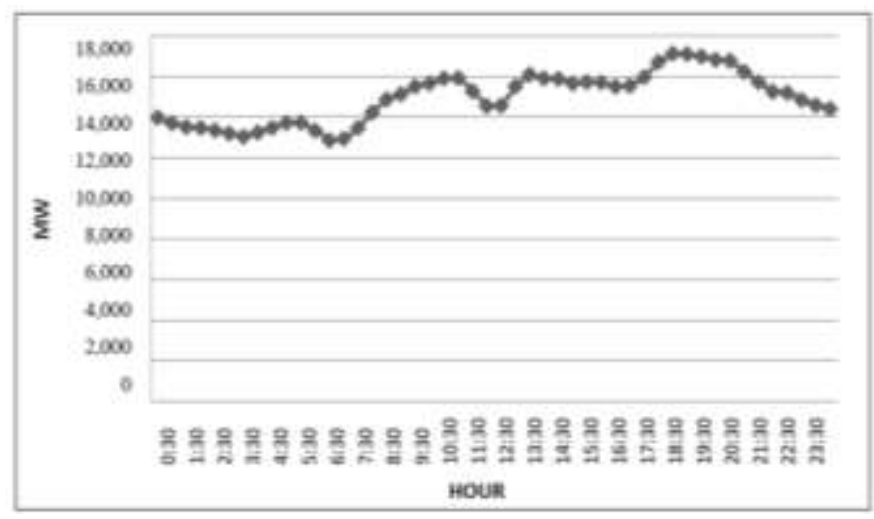

Figure 3. 24-hour electricity consumption pattern 
In this case, the data will be normalized into 0 (zero) or 1 (one). The result of the data normalization presented in the general pattern of daily electrical behavior as seen in Figure 4.

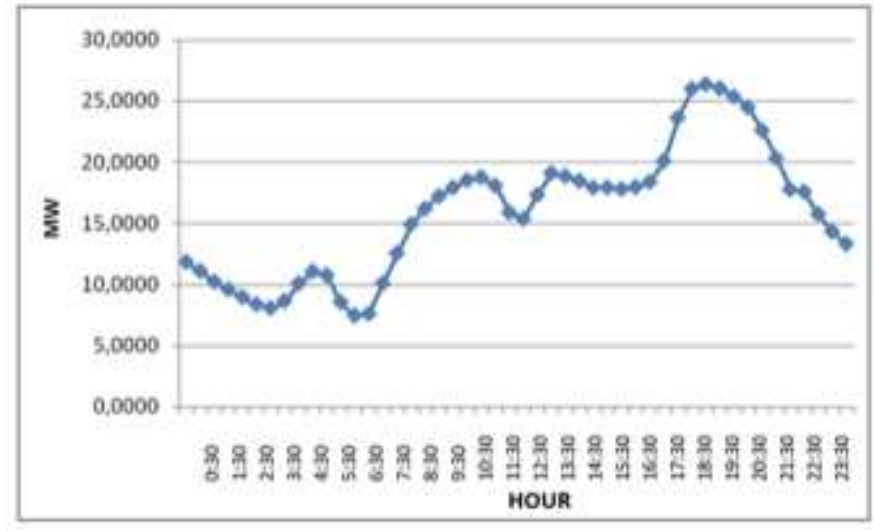

Figure 4. The general pattern of daily electrical behavior every hour after normalization

In artificial neural networks based on supervised learning paradigms, in general, 3 (three) matrices are needed. These matrices function as training data that requires training matrices and target matrices. Another matrix is a simulation matrix. Generally depicted as shown in Figure 4. These three matrices will be taken respectively based on hourly load patterns and daily load patterns. In the case of load behavior patterns, the training matrix is a $31 \times 2$ matrix for load behavior based on per 30 minutes in 24 hours. There is also a $24 \times 2$ matrix for load behavior based on weekdays and holidays. The training matrix is taken from the largest value and the smallest value from the normalized load behavior data matrix column.

\section{CONCLUSION}

This research was undertaken to design and evaluate that neural network algorithm namely ADALINE can be implemented to control household appliances as an integrated smart home system with a solar panel. When the system works automatically based on the readings of the existing sensors, ADALINE is used according to that condition in this study. This system can be controlled via Android applications that act as remote controls when in manual mode. To enable the operation of this prototype, one microcontroller is required as controller and server. The access point is needed to control all the media connected to the smart system. Integrating android-based components and applications is expected to increase the flexibility (for users) in controlling home appliances. Over and above that, the automatic controller of household devices based on sensor readings is expected to increase the efficiency of electricity usage. Based on testing and findings from the results of this study, that the IoT smart home model with the ADALINE method can be a model recommendation, as a proposal to obtain an efficient and beneficial electricity usage pattern to be implemented in a smart home.

\section{REFERENCES}

[1] V. Ricquebourg, D. Menga, D. Durand, B. Marhic, L. Delahoche. and C. Loge, "The Smart Home Concept : our immediate future," 2006 1ST IEEE International Conference on E-Learning in Industrial Electronics, 2006, pp. 2328, doi: 10.1109/ICELIE.2006.347206.

[2] F. K. Aldrich, "Smart Homes: Past, Present and Futures," in Book chap : Inside the Smart Home, R. Harper, London, UK: Springer, 2003, pp. 17-39, doi: 10.1007/1-85233-854-7_2.

[3] M. R. Alam, M. B. I. Reaz, and M. A. M. Ali, "A Review of Smart Homes-Past, Present, and Future," in IEEE Transactions on Systems, Man, and Cybernetics, Part C (Applications and Reviews), vol. 42, no. 6, pp. 1190-1203, Nov. 2012, doi: 10.1109/TSMCC.2012.2189204.

[4] V. Jyothi, M. G. Krishna, B. Raveendranadh, and D. Rupalin, "IOT Based Smart Home System Technologies," International Journal of Engineering Research and Development, vol. 13, no. 2, pp. 31-7, 2017.

[5] L. C. De Silva, C. Morikawa, and I. M. Petra, "State of the art of smart homes," Engineering Applications of Artificial Intelligence, vol. 25, no. 7, pp. 1313-1321 2012, doi: 10.1016/j.engappai.2012.05.002.

[6] E. Kamel and A. M. Memari, "State-of-the-Art Review of Energy Smart Homes," J. Archit. Eng., vol. 25, no. 1, 2019, doi: 10.1061/(ASCE)AE.1943-5568.0000337. 
[7] V. D. Vaidya and P. Vishwakarma, "A Comparative Analysis on Smart Home System to Control, Monitor and Secure Home, based on technologies like GSM, IOT, Bluetooth and PIC Microcontroller with ZigBee Modulation," 2018 International Conference on Smart City and Emerging Technology (ICSCET), 2018, pp. 1-4, doi: 10.1109/ICSCET.2018.8537381.

[8] A. Leoni, et.al., "Energy harvesting optimization for built-in power replacement of electronic multisensory architecture," AEU - International Journal of Electronics and Communications, vol. 107, pp. 170-176, 2019, doi: 10.1016/j.aeue.2019.05.002

[9] Indrianto, M. N. I. Susanti, R. R. A. Siregar, P. Putri J., and Y. Purwanto, "Smart taxi security system design with internet of things (IoT)," TELKOMNIKA Telecommunication Computing Electronics and Control, vol. 17, no. 3, pp. 1250-1255, 2019, doi: 10.12928/telkomnika.v17i3.10167.

[10] M. Abinaya and R. U. Devi, "Intelligent Vehicle Control Using Wireless Embedded System in Transportation System Based On GSM and GPS Technology," International Journal of Computer Science and Mobile Computing, vol. 3, no. 9, pp. 244-258, 2014.

[11] D. Hartanti, R. N. Aziza, and P. C. Siswipraptini, "Optimization of smart traffic lights to prevent traffic congestion using fuzzy logic," TELKOMNIKA Telecommunication Computing Electronics and Control, vol. 17, no. 1, pp. 320-327, 2019, doi: 10.12928/telkomnika.v17i1.10129.

[12] P. C. Siswipraptini, W. H. Martono, and D. Hartanti, "Reducing a congestion with introduce the greedy algorithm on traffic light control," J. Phys. Conf. Ser., vol. 974, no. 1, 2018, doi :10.1088/1742-6596/974/1/012013.

[13] J. Y. Kim, H. Lee, J. Son, and J. Park, "Smart home web of objects-based IoT management model and methods for home data mining," 2015 17th Asia-Pacific Network Operations and Management Symposium (APNOMS), 2015, pp. 327-331, doi: 10.1109/APNOMS.2015.7275448.

[14] S. Ghosh, "Smart homes: Architectural and engineering design imperatives for smart city building codes," 2018 Tech. for Smart-City Energy Security and Power(ICSESP), 2018, pp. 1-4, doi: 10.1109/ICSESP.2018.8376676.

[15] D. E. Paul and A. Vijayan, "Smart Energy Meter Using Android Application And Gsm Network," Int. J. Eng. Comput. Sci., vol. 5, no. 3, pp. 16058-16063, 2016, doi: 10.18535/ijecs/v5i3.36.

[16] B. Lashkari, Y. Chen, and P. Musilek, "Energy management for smart homes-state of the art," Applied Sciences (Switzerland), vol. 9, no. 17. 2019, doi: 10.3390/app9173459.

[17] M. Samarth Pandit, M. Snehamandhre, and M. Meghananichal, "Smart Energy Meter using internet of Things (IoT)," Vishwakarma Journal of Engineering Research, vol. 1, no. 2, pp. 222-229, 2017.

[18] P. C. Siswipraptini, R. Nur Aziza, I. B. Sangadji, I. Indrianto, and R. R. Siregar, "Automated Smart Home Controller Based on Adaptive Linear Neural Network," 2019 7th International Conference on Control, Mechatronics and Automation (ICCMA), 2019, pp. 423-427, doi: 10.1109/ICCMA46720.2019.8988733.

[19] Y. S. Tak, J. Kim, and E. Hwang, "Hierarchical querying scheme of human motions for smart home environment," Eng. Appl. Artif. Intell., vol. 25, no. 7, pp. 1301-1312, 2012, doi: 10.1016/j.engappai.2012.03.020.

[20] S. Z. Reyhani and M. Mahdavi, "User authentication using neural network in smart home networks," Int. J. Smart Home, vol. 1, no. 2, pp. 147-154, 2007.

[21] A. Bhanot and S. Badlan, "Smart Home System Design based on Artificial Neural Networks," Proceedings of the World Congress on Engineering and Computer Science 2011, vol. 1, 2011.

[22] R. R. A. Siregar, H. Sikumbang, I. B. M. Sangadji, and Indrianto, "KWh Meter Smart Card Model Token For Electrical Energy Monitoring," MATEC Web Conf., vol. 218, 2018, doi: 10.1051/matecconf/201821803002.

[23] A. Q. Leon, "5 algorithms to train a neural network," Data Science and Machine Learning Blog, 2020. [Online] Available: https://www.neuraldesigner.com/blog/5_algorithms_to_train_a_neural_network

[24] T. Bolukbasi, J. Wang, O. Dekel, and V. Saligrama, “Adaptive Neural Networks for Efficient Inference," ICML'17: Proceedings of the 34th International Conference on Machine Learning, vol. 70, 2017, pp. 527-536.

[25] R. Begg and R. Hassan, "Artificial Neural Networks in Smart Homes," J. C. Augusto, C. D. Nugent, Designing Smart Homes, London, UK: Springer, 2016, pp. 146-164, doi: 10.1007/11788485_9.

[26] D. T. Viet, N. H. Hieu, and N. M. Khoa, "A Method for Monitoring Voltage Disturbances Based on Discrete Wavelet Transform and Adaptive Linear Neural Network A Method for Monitoring Voltage Disturbances Based on Discrete," Int. Review of Electrical Engineering, vol. 11, no. 3, pp. 314-322, 2016, doi: 10.15866/iree.v11i3.8344.

[27] H. Lee and T. Kim, "Prototype of IoT enabled smart factory," ICIC Express Lett. Part B Appl., vol. 7, no. 4, pp. 955-960, 2016.

[28] B. Kang, S. Kim, M. Choi, K. Cho, S. Jang, and S. Park, "Analysis of Types and Importance of Sensors in Smart Home Services," 2016 IEEE 18th International Conference on High Performance Computing and Communications; IEEE 14th International Conference on Smart City; IEEE 2nd International Conference on Data Science and Systems (HPCC/SmartCity/DSS), 2016, pp. 1388-1389, doi: 10.1109/HPCC-SmartCity-DSS.2016.0196.

[29] J. C. Augusto and C. D. Nugent, Designing Smart Homes The Role of Artificial Intelligence, London, UK: Springer, 2006.

[30] H. D. Mehr, H. Polat, and A. Cetin, "Resident activity recognition in smart homes by using artificial neural networks," 2016 4th Int. Istanbul Smart Grid Congress and Fair (ICSG), 2016, pp. 1-5, doi: 10.1109/SGCF.2016.7492428.

[31] D. T. Viet, N. H. Hieu, and N. M. Khoa, "A Method for Monitoring Voltage Disturbances Based on Discrete Wavelet Transform and Adaptive Linear Neural Network," Int. Rev. Electr. Eng., vol. 11, no. 3, pp. 314-322, 2016, doi: 10.15866/iree.v11i3.8344.

[32] W. Ji and E. H. W. Chan, "Critical Factors Influencing the Adoption of Smart Home Energy Technology in China: A Guangdong Province Case Study,” Energies, vol. 12, no. 21, 2019, doi: 10.3390/en12214180. 